\title{
As Estações (1975), de Artavazd Peleshian: uma abordagem poética para um regime
}

\section{documental da sensibilidade}

\section{João de Deus Barreto Segundo}

Mestrando em comunicação pela Universidade Federal da Bahia.

Bacharel em Comunicação com habilitação em jornalismo pela mesma faculdade.

\begin{abstract}
Resumo: O campo de estudo do cinema documental é fervilhante de aproximações científicas para um objeto que, por excelência, é fugidio, uma vez que o filme documental geralmente se propõe a apreender a realidade tal qual ela se apresenta, sem re-encenações, assumindo assim como compromisso ético, formal e estilístico, um parâmetro indexical. O cinema documental gira, eminentemente, em torno de um discurso ou argumento construído sobre o mundo material. Dito isto, o filme As Estações (Vremena Goda, 1975), do cineasta armênio Artavazd Peleshian, foi escolhido para análise por apresentar especificidades que o tornam bastante peculiar, a saber, o fato de aparentar ser mais propriamente um registro de uma sensibilidade extrapolando o registro de fatos sociais. Para tanto, será utilizada uma metodologia de análise interna - imanente - da obra fílmica, vinculada a uma breve análise do contexto de produção, que, juntas, devem favorecer a análise final com solidez metodológica. A partir do filme e dentro do campo de estudos do documentário cinematográfico, o presente artigo objetiva entender melhor o funcionamento de um texto fílmico que busca, dentro um regime estético, se debruçar sobre o registro documental de uma realidade específica.
\end{abstract}

Palavras-chave: Análise fílmica, documentário, Artavazd Peleshian, As Estações.

Abstract: The research field of documentary cinema is very rich when it comes to scientific approaches to an object that is very tough to define. That is so for documentary film usually tries to apprehend reality such as it is, without reenacting or such, proposing an indexical parameter of filmmaking as an ethical, formal and stylerelated commitment. Documentary cinema is, eminently, about an argument built upon our material reality. Being so, Armenian Artavazd Peleshian's documentary The Stations of the Year (Vremena Goda, 1975) has been chosen to be analyzed because it presents singularities which make it a very special and meaningful piece of work, such as its resemblance to a document of a way of experiencing a reality through a particular sensibility instead of being a mere document of social facts. To analyze it, it has been used a methodology which takes a careful look on the inner mechanics of the audiovisual work along with a contextual analysis of the production process, which together must provide scientific rigor. The following paper aims to better understand how a film, which aspired aesthetically to register the way of feeling of a group of people, works.

Keywords: Film analysis, documentary film, Artavazd Peleshian, The Stations of the Year

Antes de entrar na análise do documentário escolhido, faz-se necessário um esforço conceitual para acercar a noção de documentário. Esse esforço conceitual servirá também, em tempo, para exemplificar a singularidade do corpus de análise, a saber, As Estações (1975), de Artavazd Peleshian, que se aproxima das definições vigentes de documentário e, concomitantemente, delas se destaca. De acordo com Bill Nichols (1991) e com Daí Vaughan (1988), todo documentário usualmente negocia com o realismo cinematográfico, seja como opção estilística, para modificá-lo ou para contestá-lo; afinal, é o realismo que mais frequentemente caracteriza 
o gênero documental. É uma busca por um meio transparente ao mundo e que, simultaneamente, pretende funcionar como discurso (1):

\begin{abstract}
Essas convenções guiam a nossa resposta e estabelecem um ponto de partida para o método de processamento da informação disponível no texto. Nós somos colocados em um modo diferente de engajamento, no qual o jogo ficcional que requere suspensão da descrença ('eu sei que isso é uma ficção, mas eu vou acreditar do mesmo jeito', uma contínua oscilação entre 'Sim, isso é verdade,' e 'Não, isso não é') transforma-se na ativação da crença ('É assim que o mundo é, mas poderia ser diferente'). A nossa oscilação agora se dá entre o reconhecimento da realidade histórica e o reconhecimento de um discurso sobre ela (NICHOLS, 1991: 28).
\end{abstract}

\title{
Realismo, representação realística e indexicabilidade no cinema documentário
}

O realismo no documentário se reporta à relação entre texto fílmico e referencial histórico, em um regime de indexicabilidade dos fatos históricos (sem necessariamente se eximir de uma opinião a partir da construção de um argumento sobre o mundo material), quando se busca minimizar, pela técnica cinematográfica, a resistência ao discurso de transparência e autenticidade. O realismo documental seria, pois, uma série de convenções e normas de representação visual que tendem ao apagamento da interferência humana sobre o fato histórico em si (HALL, 1988; NICHOLS, 1991; VAUGHAN, 1988).

O realismo na ficção geralmente implica em apagamento das marcas da enunciação cinematográfica como um todo, instaurando novos sistemas convencionais, e se confunde com representação realística (2), ocasionadas por soluções tanto técnicas quanto estéticas, levando em consideração o conjunto de códigos assimilados pelo público, as convenções e regras que variam culturalmente para que a imagem composta e apresentada no filme seja semelhante à percepção do real:

O realismo aparece, então, como um ganho em realidade em relação a um estado anterior do modo de representação. Esse ganho, porém, é infinitamente renovável, em conseqüência das inovações técnicas, mas também porque a própria realidade jamais é atingida (AUMONT, 1995: 135) (3).

Em contrapartida, o realismo e a representação realística no documentário negociam com um outro aspecto da realidade histórica, a sua materialidade a ser absorvida pela câmera por meio de uma relação de indexicabilidade (HALL, 1988; VAUGHAN, 1988) e uma promessa de reconhecimento pelo campo de produção e apreciação do documentário (4), mesmo que o texto fílmico documental opte por um ponto de vista mais pessoal, autoral, estilística ou retórico específico: o realismo e a representação realística, no documentário, servem para tornar um argumento sobre o mundo histórico ainda mais persuasivo (NICHOLS, 1991). A forma documental também pode incorporar conceitos como o desenvolvimento de personagens, embora eles sejam atores sociais e não atores representando deliberadamente funções e ocupando lugares narrativos, continuidade e montagem. 
A objetividade assume o papel de elo entre o mundo material e a visão do poeta (5), do criador do texto fílmico, mas não é necessariamente uma objetividade distante, pois o compromisso ético absorve graus de distanciamento distintos entre o que filma e o objeto filmado:

A interpretação se constrói sobre fatos. Suas formas e seus cânones de validação dependem da referencialidade, de uma base de evidências e da lógica documental. A retórica argumentativa deve aderir a, pelo menos, as constrições que dizem respeito à instância do objeto mesmo que elementos subjetivos, interpretativos ou emocionais sejam empregados (NICHOLS, 1991: 190).

Assim, a visão, ou mesmo o estilo narrativo no documentário, dizem respeito a como o documentarista entende e interpreta o modo como o mundo histórico, material, se apresenta. Isso não autoriza o documentarista a mentir, ou a fabricar fatos, mas certamente lhe garante alguma liberdade no tratamento que dá a uma questão a partir dos fatos observados.

O documentário, principalmente pelas escolhas estilísticas e metodológicas iniciais do campo produtivo, não teve, inicialmente, sua dimensão estética largamente estudada. O discurso que impregnava o documentário demandava empenho social na representação dos fatos históricos, porém distanciava-o do espetáculo dos melodramas que dominavam o cinema narrativo ficcional à época, sendo Hollywood seu centro produtivo. Resulta disso um certo comedimento estilístico com o intuito de obter capital no campo - e ganhos em objetividade no tratamento das questões, incorporados das linhas gerais do método etnográfico - na feitura desse tipo de material fílmico em comparação com as pirotecnias comuns à ficção do primeiro cinema e do melodrama. A intenção desse procedimento geral tem sido direcionar o olhar do público para a questão tratada e não para o modo como ela é tratada.

Apesar de não ser uma imitação (6) no sentido estrito do termo, o documentário também se propõe, a seu modo, a ser uma re-apresentação da realidade por meio do aparato cinematográfico e para isso também deve obedecer aos critérios de verossimilhança e representação realística, mesmo que estes estejam subjugados pelas marcas do autor (caso haja uma identidade específica à filmografia), às marcas de estilo e aos desafios estéticos e poéticos impostos pela abordagem técnica do texto fílmico. Os elementos textuais estarão, pois, organizados para cumprir uma função primeva que é criar sentido numa estrutura de cunho basicamente retórico, embora atado aos fatos como acontecem ou aconteceram e, talvez, sob o ponto de vista do documentarista ou da equipe realizadora.

O realismo e a representação realística no documentário estão largamente associados à filmagem em locação, sob pena de, em caso contrário, reprimir o caráter indexical do fato histórico ou social narrado e romper o compromisso ético com o campo. Do mesmo modo, enquadramentos irregulares e má captação de áudio indicam a presença do aparato de gravação e o processo produtivo, e não necessariamente a autenticidade do fato narrado, não caracterizando portanto uma estética do documentário (HALL, 1988; NICHOLS, 1991) (7). 


\section{Hipóteses fundamentais}

São duas as hipóteses fundamentais que guiam este estudo:

a) O documentário As Estações (Vremena Goda, 1975) observa e tece um argumento sobre uma forma de vivenciar o cotidiano em um modo de vida rural na Armênia. Seu caráter indexical está não apenas em registrar fatos sócio-históricos como aconteceram diante da câmera, mas o modo como estes fatos tendem a se desenvolver naquele ambiente rural no período registrado.

b) À medida que retrata o modo de vida rural do interior da Armênia - e a relação entre o homem e o ambiente natural -, o texto fílmico projeta uma dimensão estética (do domínio da sensibilidade) que vai além de uma indexicabilidade do fato sócio-histórico e que, permeando o tecido fílmico, poderia assumir o caráter de retrato do modo de o elemento humano geralmente relacionar-se - controlando ou se submetendo - com as imprevisibilidades do ambiente natural em qualquer região rural distante das atuais tecnologias agrícolas.

\section{Metodologia de análise}

A Poética do filme (GOMES, 1996) não é uma teoria geral da interpretação do filme, é uma perspectiva analítica capaz de orientar a visão do analista e o discurso sobre a obra cinematográfica apoiado em uma teoria do funcionamento do texto fílmico. Propõe-se, antes de qualquer outra coisa, a identificação daquilo que compõe a experiência fílmica, daquilo que o filme frequentemente faz com os seus espectadores, o que emerge da cooperação entre intérprete e texto.

Os materiais que compõem a obra fílmica são muito variados. Incluem desde aspectos plásticos como paleta cromática e composição - foco, distribuição dos elementos, posição dos objetos - a aspectos fotográficos tais como enquadramento, escala de planos, nitidez, contraste, textura, tonalidade, brilho, fonte de luz, movimentos de câmeras etc. Incluem todos os aspectos acústicos, da música ao som; e ainda a direção dos atores, os cenários, figurinos. No que diz respeito aos parâmetros narrativos, tem-se o argumento e o enredo, as peripécias, os desenlaces. Tais materiais e técnicas são meios para a produção do filme e são estruturados com o intuito de produzirem certos efeitos no espectador.

No que diz respeito propriamente à análise, não há a liberdade de transformar qualquer coisa em texto ou expressão. Significar é sempre significar para um intérprete, mas quem determina o que pode ser interpretado e como pode ser interpretado são as regras postas na obra, e não a vontade de quem interpreta. Qualquer obra artística é também material expressivo, solicita a atividade interpretativa por parte do espectador, capaz de converter a obra artística em material interpretativo.

Os efeitos que as obras expressivas podem realizar prevêem e solicitam a subjetividade do apreciador em pelo menos três das suas dimensões fundamentais: cognitiva, sensorial e afetiva. São solicitados do espectador na seguinte ordem: informação, ou fazer o espectador pensar em algo, trazer algo à mente do intérprete: os conteúdos. Os estímulos são também de natureza sensorial, ou seja, prestam-se a provocar sensações, construir 
certas disposições sensoriais. E, por último, expressar é produzir um estado emocional, de ânimo, um sentimento, construir um estado de espírito. A perspectiva de todo autor e de toda obra é de que a apreciação pode ser programada, porém o artista não é dono da apreciação que será feita de sua obra. $\mathrm{O}$ artista, tomando sua apreciação como o modelo de apreciação dos demais, espera ter controle sobre o que programa. Daí em diante existe apenas a obra, que, ao ser concluída, tampouco está submetida ao arbítrio do apreciador. Os efeitos são executados pelo apreciador seguindo as trilhas de leitura, que embora inicialmente programadas pelo autor, pertencem unicamente à obra, que rege os parâmetros da sua própria interpretação.

Primeiramente, a obra é apreciada e só então é interpretada. A partir da interpretação estabelece-se um procedimento crítico, que não objetiva apenas o desfrute estético, mas o aumento do conhecimento reflexivo sobre a obra fílmica e sobre cinema. Ao analista cabe então separar o que é realmente da obra daquilo que representa mais um investimento exclusivamente subjetivo de sua parte. $\mathrm{O}$ analista pretende apreender a obra não apenas no que ela faz a si, mas no que faria costumeiramente a qualquer outro espectador. O procedimento de apreciação e análise inverte o processo de criação.

Por fim é fundamental dizer ainda que o contexto, o conjunto de outras obras relacionadas, o universo dos produtores e das condições sociais da produção podem facilitar a compreensão da obra, o conhecimento de sua mecânica, oferecendo informações adicionais ao procedimento de análise. Essa observação vale especialmente para o texto fílmico documental, que está mais atado ao mundo material do que a ficção, tanto em seu momento de produção quanto de apreciação (8).

\section{Análise de As Estações}

Dos modos de representação mais comuns ao cinema documental, As Estações (1975) (9), à primeira vista se aproximaria mais do regime observacional. De acordo com Nichols (1991), o documentário observacional é aquele que usa imagens e sons captados no local da ação, em contraste com o voiceover e as imagens de ilustração do modo documental expositório, modelo formal que não propõe um vínculo direto com o momento na filmagem. Portanto, o documentário observacional costuma se reportar a experiências mais contemporâneas:

\footnotetext{
A ausência de comentário e a relutância em usar imagens para ilustrar generalizações encoraja uma ênfase na atividade de indivíduos dentro de formações sociais específicas tais como a família, a comunidade local ou uma instituição [...]. Tais observações frequentemente tomam forma ao redor de representações de tipicidade - os tipos de intercâmbios e atividades que são mais suscetíveis de ocorrer (High School), processos - o desenrolar de relacionamentos no decorrer do tempo (An American Family), ou uma crise - a conduta de indivíduos sob pressão (Primary) (NICHOLS, 1991: 40).
}

A semelhança do cinema observacional com o método etnográfico reside no fato de que ambos pressupõem um modo de observação não julgamental, empático que seja capaz de atenuar a postura de autoridade convencional 
atribuída a quem está com a câmera ou com o caderno de notas. O filme não é totalmente objetivo, porém objetifica, enfatizando-se assim a estruturação que acontece não apenas na filmagem do material, mas em cada processo seletivo relacionado ao texto fílmico. Assume-se que toda narrativa, documental ou não, está fundamentadas em um processo de seleção. Se o fato de alguém estar filmando muda o comportamento, devese decidir metodologicamente se a mudança é ou não relevante ao retrato geral objetivo que se busca no texto fílmico e à economia tanto da narrativa quanto da retórica do filme (10).

Artavazd Peleshian nasceu em 22 de fevereiro de 1938 em Leninakan, Armênia, que então pertencia à extinta União das Repúblicas Socialistas Soviéticas. Estudou na escola de cinema russa VGIK (hoje chamada de Instituto Gerasimov de Cinematografia), em Moscou, entre 1963 e 1968, onde provavelmente entrou em contato com o trabalho e as teorias sobre o cinema de Sergei Eisenstein. As referências biográficas aqui se tornam importantes porque Peleshian atribui um conjunto de marcas significativas ao seu trabalho que o identificam no campo do documentário enquanto autor. Essas marcas tendem a se repetir com frequência em sua filmografia e o localizam dentre o conjunto de cineastas herdeiros do cinema soviético, ou em outras palavras, coloca-se como um autor na obra (BUSCOMBE. 2005; HEATH, 2005).

Faz-se necessário falar sobre a origem do autor de As Estações porque o olhar dele será o olhar do armênio soviético sobre a vida rural típica da Armênia soviética. Estando inserido naquela cultura, supõe-se que Peleshian tenha empregado um olhar mais propriamente etnográfico, que não o distancie tanto dos sujeitos observados a ponto de transformá-los em objetos e que o distancie o suficiente a ponto de lhe oferecer alguma objetividade no tratamento do material fílmico: esse olhar deve tipificá-los cinematograficamente sem destituir-lhe os relevos próprios de sua cultura.

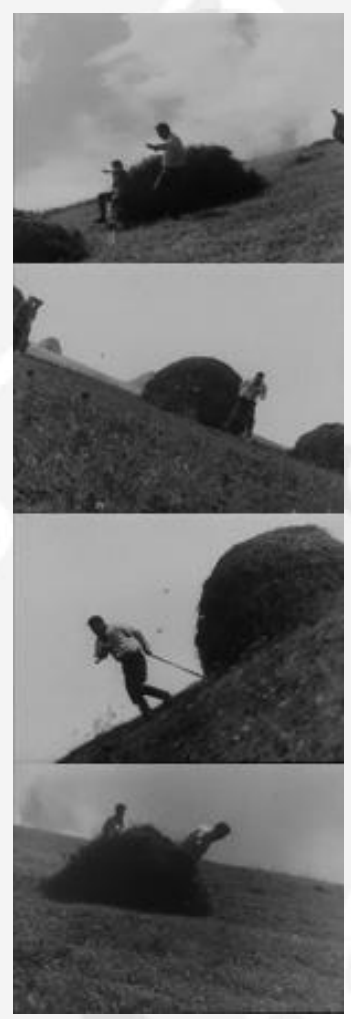


O filme tem início com uma montagem de planos curtos compostos por homens e ovelhas descendo uma correnteza. Não é informado ao leitor se é o mesmo homem ou uma sucessão de indivíduos distintos, o que é proposital e inerente ao programa de efeitos do filme. Na banda sonora, é informado apenas o barulho de água corrente, provavelmente, captado diretamente no local. Nesse primeiro bloco narrativo, à guisa de introdução a argumentação da obra, instauram-se dois dos dispositivos que serão marcantes no desenvolvimento do feixe de peripécias da narrativa. A saber, o primeiro é a montagem de planos dando idéia de repetição, para demarcar que a vida rural é uma vida que abarca rotinas bem delimitadas que se repetem no tempo.

Com freqüência, é o mesmo plano invertido horizontalmente na edição e montado sobre o anterior em cortes secos. Às vezes, são planos diferentes, geralmente fixos ou que giram levemente sobre o próprio eixo, com atores sociais diferentes, mas realizando a mesma ação disposta de forma vetorial, seja diagonalmente da direita para a esquerda, da esquerda para a direita ou de cima para baixo (vide fig. 1). As ações vetoriais são encaixadas de modo intercalado na montagem. O modo de construir significação entre planos por contraposição a outros planos segue o modelo de montagem do cinema de Sergei Eisenstein (EISENSTEIN, 2002a):

Nossos sentidos apreendem a atração de cada plano e nossos desejos interiores compartilham essas atrações através de semelhança ou do contraste, criando uma unidade superior e uma interação de planos específicos (no nível da extensão, do ritmo, do tom, do sobretom ou da metáfora) que produz significado. A montagem é, para Eisenstein, o poder criativo do cinema, o meio através do qual as 'células' isoladas se tornam um conjunto cinemático vivo; a montagem é o princípio vital que dá significado aos planos puros (ANDREW, 2002: 53).

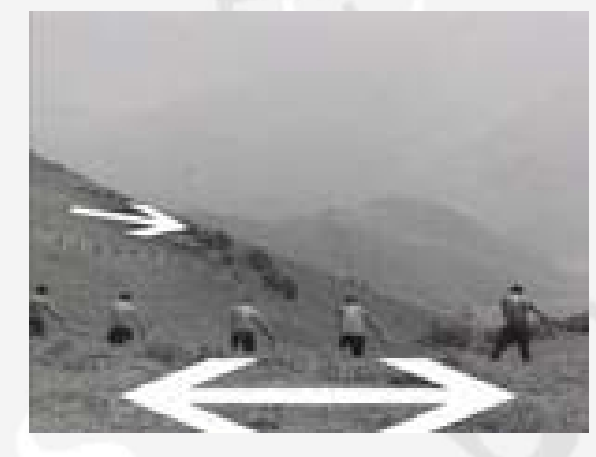

Peleshian usa o princípio da montagem de atrações, sem aplicá-lo em sua totalidade a todos os elementos cinematográficos disponíveis. Opta por compor um tecido fílmico mais harmônico, sem tantos choques e colisões entre os mais diversos componentes como argumentava e propunha Eisenstein. Para tal, direciona sua atenção apenas para uma montagem de atrações na paleta de cores e nos planos, as "células" que compõem o tecido do filme (EISENSTEIN, 2002a, 2002b). Com alguma recorrência, a composição do plano segue o 
princípio da montagem de atrações, incluindo no mesmo quadro duas séries de ações análogas, porém vetorialmente distintas, como na figura 2.

A composição de plano é um elemento muito importante para a construção de sentido de As Estações. Os planos tendem a ser preenchidos de sentido e como não há diálogos ou legendas mais objetivas, o ordenamento dos planos também almeja um encadeamento lógico e discursivo bastante deliberado. Para apresentar o cenário onde se desenvolverá a ação, por exemplo, o autor-modelo opta por mostrar, nesta ordem, um penhasco, uma vila escavada na encosta escarpada do penhasco, um telhado em plano próximo, a sacada sob o telhado, e finalmente rostos humanos em close e mãos em plano detalhe, nos quais se ressalta as alianças de casamento tema que será retomado mais adiante no texto do documentário -, um plano preenchido por ovelhas, depois pessoas entre as ovelhas, e pessoas seguindo a sua rotina rural (vide fig. 3, abaixo), encaixando assim o elemento humano entre os elementos naturais circundantes.
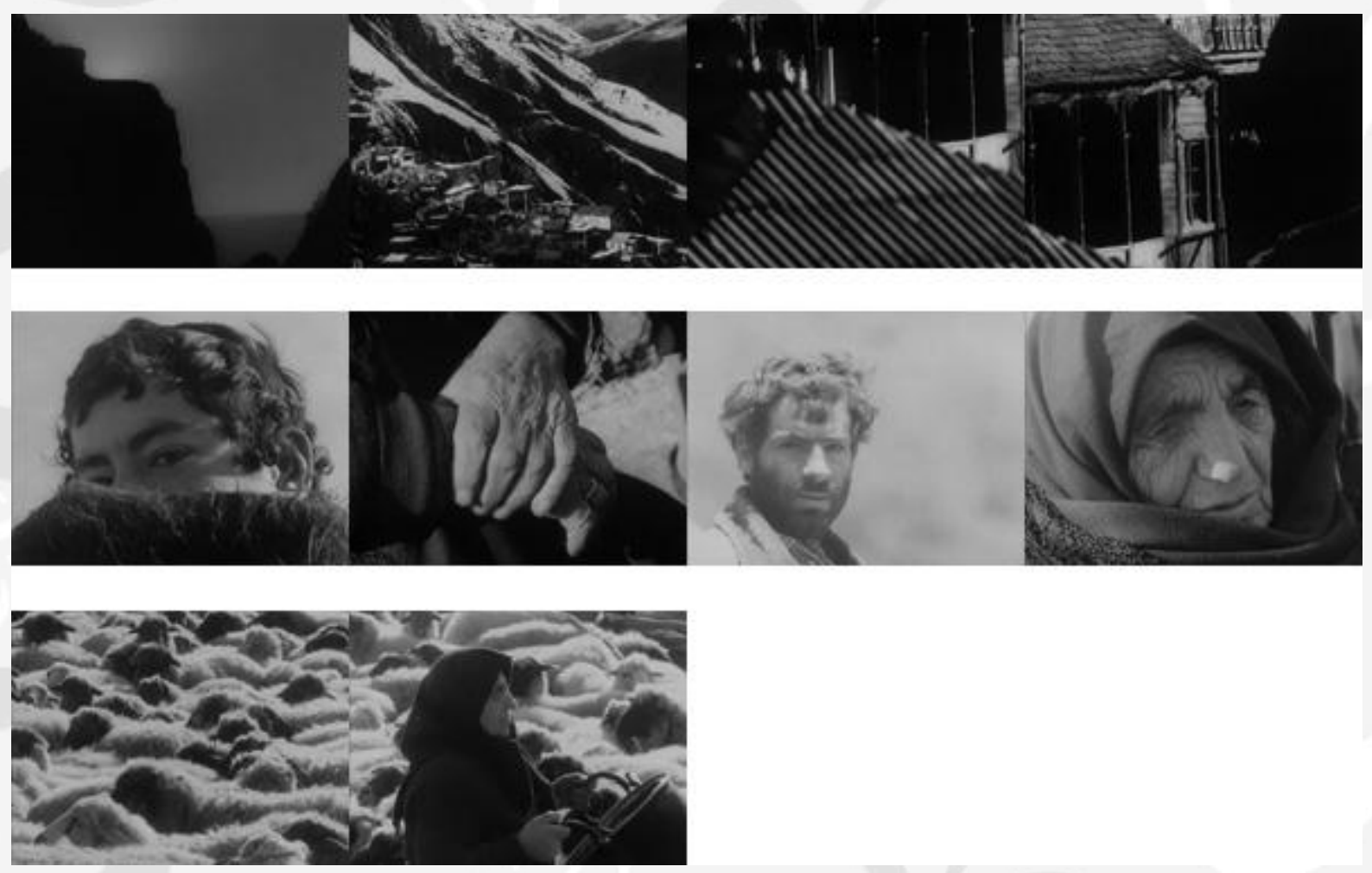

Configura assim uma rotina de mostração, do maior e mais geral para o menor e mais específico e vice-versa, a depender do grau de distanciamento ou inserção pretendido para o leitor-modelo no momento da narrativa. Por vezes, o plano coloca o apreciador no meio do rebanho de ovelhas, de gado, sob a chuva intensa a ponto de encobrir a visão através do quadro, e quando faz isso, o plano é organizado na altura literalmente de um olhar humano e o som torna-se direto. É o som do acontecimento tal qual ele se deu, convocando o espectador e experimentar a ação sensorialmente. Outras vezes, o leitor é distanciado fisicamente da ação, tendo o seu ponto 
de vista estabelecido acima da correnteza, sobre o deslizamento de neve, contemplando um penhasco nebuloso ou a própria vila na encosta ao longe.

O segundo dispositivo é a substituição da velocidade natural do acontecimento por uma velocidade mais baixa, organizando um tempo narrativo mais distendido, que atua na construção do discurso sobre a passagem do tempo no modo de vida rural armênio. Já em um minuto de projeção, sobe, na banda sonora, uma música mais lenta, de teor melancólico, à medida em que ocorre a substituição súbita de velocidade na mostração da ação por meio da redução da velocidade dos fotogramas por segundo. A música é empregada de modo recorrente para atribuir ritmo e lirismo às cenas, sincronizando o tempo de ação no plano com o tempo de duração de uma frase musical (aos 9'15', e aos 9'36' esse recurso se mostra mais explicitamente), criando uma atmosfera mais melancólica, ou mais alegre, atuando como elemento unificador do discurso sobre a unicidade e o equilíbrio obtido por aquele agrupamento humano e o ambiente que o circunda. Para tanto, As Estações, de Vivaldi, é usada de modo recorrente.

O terceiro dispositivo acontece no âmbito temático, decorrente do ordenamento das sequências de planos na mostração. Há um grande tema que é a relação entre o homem e natureza, a qual a narrativa argumenta ser harmônica, uma vez que o elemento humano está submetido à força das intempéries e esforça-se para conviver com esses fatos unificando-os à sua própria existência. Sobre este tema maior, discursam os temas secundários. São eles: o modo de vida pastoril independentemente do tempo atmosférico (chuva intensa, sol, neve); o casamento para a continuidade da comunidade; e a passagem do tempo como entidade inexorável, ao qual estão todos resignadamente subjugados. O dispositivo temático funciona pela intercalação de planos envolvendo elementos culturais (homens, casamento), planos envolvendo elementos naturais (nuvens, penhasco, aldeia no penhasco) e homens trabalhando sobre a natureza (homens arando o campo, chuva castigando os homens durante o translado do feno pelos campos aos 14'30', a correnteza levando ovelhas, homens lutando contra a correnteza para proteger as ovelhas).

O bloco narrativo mais eficaz e que conclui essa linha argumentativa no texto fílmico é a montagem, no terço final, que coloca em um primeiro momento os noivos e a festa do casamento em evidência logo depois da exibição da tempestade (em 18’35',), indicando que a rotina sempre segue e que aquele mesmo indivíduo, continuará com as suas ações rotineiras depois da celebração de seu casamento. Aos 23 minutos, o noivo aparece dentro da correnteza. Seguem-se planos de homens deslizando na neve com ovelhas, para baixo, como a vida, sempre seguindo os seus ciclos banais até o fim. A música retoma a atmosfera melancólica e os planos vão se tornando cada vez mais aproximados. Então, a montagem intercala cenas do casamento com cenas da correnteza em câmera lenta e a narrativa encerra aí a sua dissertação, e assume sua dimensão lírica, esteticamente orientada. 


\section{Conclusão}

O documentário, em geral, esforça-se em minimizar a representação (imitação, ficção no sentido estrito aristotélico) por intermédio da remoção de elementos idealizadores. Peleshian, nesse aspecto, vai em um vetor contrário, ao repetir, na montagem, alguns planos envolvendo ações em direções distintas, vetoriais, de modo a obter o argumento sobre a repetição, sobre a rotina rural.

As Estações está em preto e branco e, em algumas cenas, com saturação nos contrastes, eliminando a maior parte do cinza da paleta cromática, o que, com a ausência de legendas ou alguma introdução identificando propriamente o local onde se passa a narrativa, proporciona uma aura de deslocalização geográfica e temporal da história, como antigos fotogramas em sépia ou em preto e branco. Essa aura é fundamental à implantação de uma atmosfera universalista ao modo de vida rural representado porque funciona na construção da narrativa enquanto documento de um fato ao mesmo tempo em que traz experiência para o espectador (DEWEY, 1985). A ação que se desenvolve poderia acontecer em qualquer outro lugar rural montanhoso que não a Armênia.

Portanto, as duas hipóteses fundamentais deste artigo procedem. O argumento da passagem do tempo é construído por meio da mostração de uma série de ações rotineiras organizadas pela montagem e pela música, ocorridas sob sol e sob chuva, de manhã e à noite, dando idéia de sucessão de tempo e de estações. Deste modo, o argumento evoca e requer do espectador uma disposição de ânimo contemplativa e imbuída de complacência e lirismo, que se organiza em torno de predicados estéticos próprios da noção de belo (PAREYSON, 1997). Este aspecto de As Estações transcende o regime puramente indexical do texto documental e o eleva a categoria de representação de um sistema estético, da ordem própria do sentir, o que é respaldado metodologicamente pela dimensão emocional do texto. A programação emocional da obra atua principalmente nesta camada, suscitando um sentimento de felicidade ingênuo pelo desenrolar das ações submetidas aos caprichos do tempo e da natureza, em um discurso quase árcade. Assim, o discurso do documentário transcende o regionalismo daquele modo de vida rural para tornar-se discurso sobre a obtenção de equilíbrio do elemento humano perante a inexorabilidade dos elementos naturais.

\section{Notas}

(1) "Indeed, we may now perhaps rephrase our description of the documentary impulse as: a movement toward mystical union between putative and profilmic events and between profilmic event and diegesis - unions that though may be approached, may never be consummated" (VAUGHAN, 1988: 43).

(2) O realismo temático marcou, por exemplo, a escola neo-realista italiana, então se faz necessário falar em verossimilhança como marca que distingue o possível do plausível e distinguir entre realismo e representação realística. A saber, um filme pode não ser realista no seu escopo temático, mas pode ser capaz de obter uma representação realística por obedecer aos princípios tratados por Aumont no respeito aos códigos culturais de cada época. Em outras palavras, todo filme realista tende a ser organizado sob os parâmetros de uma representação realística, porém representações 
realísticas podem ser encontradas em filmes de temática irrealista, que funcionam em mundos possíveis ficcionais fantásticos organizados por verossimilhança e pacto ficcional entre leitor e obra (AUMONT, 1995).

(3) Para Nichols, há três níveis de realismo que se reportam à verossimilhança: o empírico, o psicológico e o histórico. O primeiro concerne o recorte de elementos da realidade, encaixados de volta nas narrativas, tais como réplicas das armas e de alguns costumes romanos em Ben-Hur e Spartacus. O realismo empírico recria as coisas como se espera que elas sejam na realidade e nem sempre como elas o são ou foram. O realismo psicológico é auto-explicativo: arregimenta um senso de plausibilidade às ações humanas inscritas na narrativa, mesmo que as ações sejam funções narrativas e não réplicas de comportamentos reais, como na escola Expressionista alemã. O realismo psicológico costuma ser bastante recorrente no cinema ficcional porque dele depende, em grande parte, o pacto ficcional entre leitor e texto fílmico. O realismo psicológico se estabelece também como uma forma de transparência entre a representação e o engajamento emocional, entre o que se percebe e as coisas tal como são, causando sentimentos e sensações no público que são de ordem estética. O realismo histórico, como o nome indica, reporta-se ao elo indexical entre realidade e documentação da realidade no meio audiovisual, entre referente e imagem, um dos mais importantes específicos do documentário (NICHOLS, 1995). A representação realística é facultativa nesses três tipos de realismo descritos por Nichols, porém ela só deve ser compulsória no realismo histórico.

(4) "In traditional documentary, the profilmic event is only partially effaced (effaced only insofar as it is rehearsed or reconstructed) behind a diegesis that is held to mirror a putative event conceived as general or typical -its generality being, in fact, a measure of its distance from the profilmic, since in no other sense than the general can an event be considered putative behind a reconstruction" (VAUGHAN, 1988: 42).

(5) Hall pondera, porém que a objetividade funciona como ficção operacional, porque a própria seleção de material envolve critérios subjetivos. A objetividade funcionaria mais como uma linha guia a qual o documentarista observa no seu trabalho (HALL, 1988).

(6) Aristóteles fala sobre o poético através da indicação de propriedade comum a toda espécie de poesia (ou criação), a mimesis, que resulta em simulação das ações humanas, a ficção. Eis o recorte aristotélico para pensar a realização artística. Obra significa efeitos, operar efeitos. "Ficção" vem de fazer: uma coisa ficcional é uma coisa feita, ou res ficta. Uma obra ficcional, em sentido mais amplo, é uma coisa feita para produzir efeitos (GOMES, 1996). O texto fílmico documental também é uma coisa feita e que pressupõe efeitos e acionam o intérprete em três dimensões possíveis: cognitiva (tecendo argumentos sobre a realidade), sensorial (organizando sensações) e emocional (dispondo das emoções do leitor modelo). Em sentido amplo, reproduzir a realidade é reencená-la.

(7) Um exemplo em favor deste argumento é a grande quantidade de filmes ficcionais (especialmente os de horror) que se têm apoiado nesses "defeitos" que se tornaram populares historicamente entre os registros documentais para obter uma maior verossimilhança em suas narrativas, que se passam em mundos próprios especificamente construídos para abrigálas (FELIPE, 2001; GOODMAN, 1995; GOMES, 1992, 1996).

(8) "The distiguishing mark of the documentary may be less intrinsic to the text than a function of the assumptions and expectations brought to the process of viewing the text" (NICHOLS, 1991: 24).

(9) Título: As Estações. Título original: Vremena goda. Ano: 1975. Direção e roteiro: Artavazd Peleshian. Duração: 29 minutos. País de origem: União Soviética. Língua: Armênio. Cor: Preto \& branco. 
(10) "A documentary aware of its own artifice is one that remains sensitive to the flow between fact and fiction. It does not work to conceal or exclude what is normalized as 'nonfactual', for it understands the mutual dependence of realism and 'artificiality' in the process of filmmaking. It recognizes the necessity of composing (on) life in living or making it" (MINH-HA, 1993: 99).

\section{Referências bibliográficas}

ANDREW. James D. As principais teorias do cinema. Rio de Janeiro: Jorge Zahar, 2002.

AUMONT, Jacques et. al. A estética do filme. Campinas: Papirus, 1995.

BUSCOMBE, Edward. "Idéias de autoria”. In: RAMOS, Fernão P. (org.). Teoria contemporânea do cinema. Pós-estruturalismo e filosofia analítica. V. 1, São Paulo: Senac, 2005.

DEWEY, John. Arte e experiência. São Paulo: Abril, 1985.

EISENSTEIN, Sergei. A forma do filme. Rio de Janeiro: Jorge Zahar, 2002.

. O sentido do filme. Rio de Janeiro: Jorge Zahar, 2002.

FELIPE, Fernando de. "El ojo resabiado (de documentales falsos y otros escepticismos escópicos)". In: SÁNCHEZ-NAVARRO, Jordi e HISPANO, Andrés Hispano (orgs.). Imágenes para la sospecha. Falsos documentales y otras piruetas de la no-ficción. Barcelona: Glénat, 2001.

GOMES, Wilson. "As estratégias de produção de encanto. O alcance contemporâneo da poética de Aristóteles”. In: Textos de Cultura e Comunicação, v. 35. Bahia, 1996.

. "Metáforas da diferença: A questão do inteiramente outro a partir da teoria da construção". In: Trans/Form/Ação: Revista de Filosofia, v. 15. São Paulo: Unesp, 1992.

. "La poética del cine y la cuestión del metodo en el análisis fílmico". In: Significação, v.21. Curitiba, 2004.

- "Princípios de Poética (com ênfase na poética do cinema)". In: PEREIRA, M.; GOMES, R.; FIGUEIREDO, V. (Org.). Comunicação, representação e práticas sociais. Rio de Janeiro, 2004.

GOODMAN, Nelson. Modos de fazer mundos. Porto, Portugal: Edições Asa, 1995.

HALL, Stuart. "Media Power: the Double Blind”. In: ROSENTHAL, Alan. New Challenges for Documentary. Berkeley and Los Angeles: University California Press, 1988.

HEATH, Stephen. "Comentários sobre Idéias de autoria". In: RAMOS, Fernão P (org.). Teoria contemporânea do cinema. Pós-estrututuralismo e filosofia analítica.. V. 1. São Paulo: Senac, 2005.

MINH-HA, Trinh T. "The Totalizing Quest of Meaning”. In: RENOV, Michael (org.). Theorizing Documentary. New York/London: Routledge, 1993.

NICHOLS, Bill. Representing Reality. Bloomington, Indiana: Indiana University Press, 1991.

PAREYSON, Luigi. Problemas da estética. São Paulo: Martins Fontes, 1997.

VAUGHAN, Daí. "Television Documentary Usage". In: ROSENTHAL, Alan. New Challenges in Documentary. Berkeley, Los Angeles: University of California Press, 1988. 
YOUNG, Colin. "Observational Cinema”. In: HOCHINGS, Paul (editor), Principles of Visual Anthropology. Berlin/New York: Mouton de Gruyter, 1995.

\section{Outras obras consultadas}

GAUDREAULT, André; JOST, François. El relato cinematográfico. Barcelona: Paidós Comunicación, 1995.

HEUSCH, Luc de. "The Cinema and Social Science: A Survey of Ethnographic and Sociological Films". In: Visual Anthropology. V. 1. Harrwood Academic Publishers, 1988.

JOST, François. El ojo-cámara. Entre film y novela. Argentina: Catálogos S.R.L., 2002.

KRACAUER, Sigfried. Theory of Film: The redemption of physical reality. Princeton, New Jersey: Princeton University Press, 1997.

MITRY, Jean. The Aesthetics and Psychology of the Cinema. Bloomington, Indiana: Indiana University Press, 2000.

RAMOS, Natália. "Comunicação, cultura e interculturalidade: para uma comunicação intercultural”. In: Revista Portuguesa de Pedagogia, n. 2, 2001.

RUOFF. Jeffrey K. "Conventions of Sound in Documentary". In: ALTMAN Rick. Sound Theory, Sound Practice. New York/London: Routledge, 1992.

SINGER, Ben. Melodrama and Modernity. Early Sensational Cinema and its Contents. New York: Columbia University Press, 2001

WINSTON, Brian. Claiming the Real: The Griersonian Documentary and its Legitimations. London: British Film Institute, 1995. 